\title{
Effects of organic additives on microstructure and mechanical properties of porous $\mathrm{Si}_{3} \mathrm{~N}_{4}$ ceramics
}

\author{
YU FANGLI, WANG HUANRUI, YANG JIANFENG* and GAO JIQIANG \\ State Key Laboratory for Mechanical Behaviour of Materials, Xi'an Jiaotong University, Xi'an 710049, P.R. China
}

MS received 16 December 2008; revised 17 January 2009

\begin{abstract}
Green bodies of porous $\mathrm{Si}_{3} \mathrm{~N}_{4}$ ceramics were shaped by extrusion technique using different organic additives as binder during extrusion molding. Different porosity, microstructures and mechanical properties after the extrusion, drying, debinding and sintering stages were investigated. The solid slurry content of 7075\% and extrusion pressure of 0.5-1.0 MPa had played a decisive role in the smooth realization of extrusion molding. The porous $\mathrm{Si}_{3} \mathrm{~N}_{4}$ ceramics were obtained with excellent properties using $4 \%$ hydroxypropyl methyl cellulose (HPMC) as binder and polyethylene glycol (PEG) of molecular weight, 1000, as plasticizer with a density of $1.91 \mathrm{~g} \mathrm{~cm}^{-3}$, porosity of $41.70 \%$, three-point bending strength of $166.53 \pm 20 \mathrm{MPa}$, fracture toughness of $2 \cdot 45 \pm 0 \cdot 2 \mathrm{MPa} \mathrm{m}^{1 / 2}$ and Weibull modulus (m) of $20 \cdot 75$.
\end{abstract}

Keywords. Organic additives; processing; microstructure; mechanical properties; porous $\mathrm{Si}_{3} \mathrm{~N}_{4}$ ceramics; Weibull distribution.

\section{Introduction}

Porous $\mathrm{Si}_{3} \mathrm{~N}_{4}$ ceramics is a prominent filtering material due to its excellent mechanical, high-temperature thermal and chemical stability (Kawaia and Yamakawa 1997; Shigegaki et al 1997). Porous $\mathrm{Si}_{3} \mathrm{~N}_{4}$ ceramics with high porosity are of interest for engineering applications, as gas filters, separation membranes, and catalyst supports at high temperature (Haslam et al 2000; Oh et al 2000; Corbin et al 2001). Many studies have been devoted into the molding methods of porous $\mathrm{Si}_{3} \mathrm{~N}_{4}$ ceramics, such as compression molding, injection molding, isostatic pressing, slip casting and extrusion. Also it is clear that people have paid more attention to extrusion recently, actually, extrusion, a shaping technique mainly used to produce ceramic items with a constant cross-sectional area, can be used to replace the current shaping methods in some fields because of its high throughput and ability to fabricate complex products (Raupp-Pereira et al 2007; Kaya and Butler 2002; Isobe et al 2006, 2007). Furthermore, the manufacturing cost of porous $\mathrm{Si}_{3} \mathrm{~N}_{4}$ ceramics can be lowered substantially by extrusion, thus making their widespread industrial applications possible. In extrusion process, selection of binder plays a crucial part in preparing extrusive plastic paste. It is reported that several groups of organic additives have been used as binder in extrusion of ceramics (Treischel and Emrich 1946). However, a few papers about the effect of organic additives on microstructure and mechanical properties of porous $\mathrm{Si}_{3} \mathrm{~N}_{4}$

\footnotetext{
*Author for correspondence (yang155@mail.xjtu.edu.cn)
}

ceramics were presented with an in-depth discussion. On the other hand, the binder usually is removed thermally from green body before sintering, so it means that organic additives also can be utilized as a pore former in a certain extent.

In the present study, green bodies of porous $\mathrm{Si}_{3} \mathrm{~N}_{4}$ ceramics were shaped by extrusion technique using different organic additives such as carboxymethyl cellulose (CMC, viscosity, 800 1200), methyl cellulose (MC), and hydroxypropyl methyl cellulose (HPMC) as binder. Different microstructures and mechanical properties after the extrusion, drying, debinding and sintering stages were investigated and the feasibility of using organic additives as extrusion additives to prepare porous $\mathrm{Si}_{3} \mathrm{~N}_{4}$ ceramics was evaluated in detail.

\section{Experimental}

\subsection{Preparation of samples}

Commercially available $\mathrm{Si}_{3} \mathrm{~N}_{4}$ powder (Shanghai Junyu Co. Ltd., Shanghai, China; $\alpha-\mathrm{Si}_{3} \mathrm{~N}_{4}$ ratio: $>95 \%$, mean particle size: $1.2 \mu \mathrm{m}$, main impurities by weight: $\mathrm{O}=$ $1.6 \% ; \mathrm{C}<0.2 \% ; \mathrm{Cl}, \mathrm{Fe}, \mathrm{Ca}$, and $\mathrm{Al}_{2} \mathrm{O}_{3}<80 \mathrm{ppm}$ ) was selected for use in this study. $\mathrm{Y}_{2} \mathrm{O}_{3}$ and $\mathrm{Lu}_{2} \mathrm{O}_{3}$ were used as sintering additives, CMC, MC, and HPMC as binder, and polyethylene glycol (PEG) as plasticizer. Castor oil was selected as lubricant to reduce the friction force between $\mathrm{Si}_{3} \mathrm{~N}_{4}$ particles, and glycerol as moisturizing agent.

Figure 1 shows a flow diagram for fabricating porous silicon nitride ceramics. 5 wt. $\% \mathrm{Y}_{2} \mathrm{O}_{3}$ or $\mathrm{Lu}_{2} \mathrm{O}_{3}$ and 


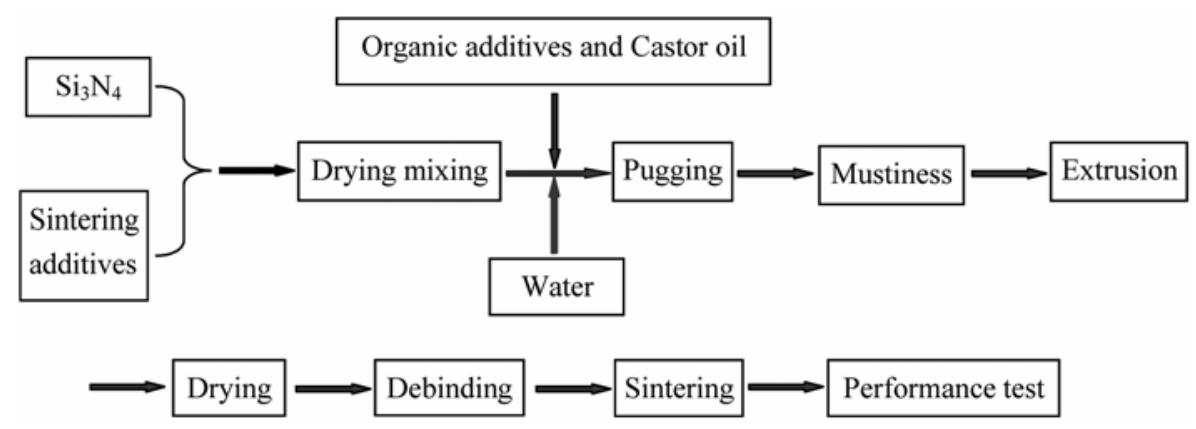

Figure 1. Flow diagram for fabricating porous silicon nitride samples.

$\alpha-\mathrm{Si}_{3} \mathrm{~N}_{4}$ powders were firstly dry mixed in a planetary mixer for $2 \cdot 5 \mathrm{~h}$. Pro rata organic additives, castor oil and water were added into the dry mixture. The obtained mixture was then kneaded in an alumina mortar with a pestle for $20 \mathrm{~min}$, providing a high-shear mixing to break up agglomerates and obtain homogeneous paste. Then the resulting paste was decayed for $12 \mathrm{~h}$ and extruded to form the rods, $8.8 \mathrm{~mm}$ in diameter, through a homemade pistontype extruder (barrel diameter: $25 \mathrm{~mm}$, length of die land: $12 \mathrm{~mm}$, entrance angle of conical die: $31 \cdot 8^{\circ}$ ) at room temperature. The extrusion force was exerted by a tabletop testing machine (Instron 1195, Instron Co., Buckinghamshire, England), which allowed the extrusion force to be recorded as a function of piston displacement. The moving velocity of piston was $20 \mathrm{~mm} / \mathrm{min}$. The testing machine also was used to measure three-point bending strength below. The extruded rods were subsequently cut into about $40 \mathrm{~mm}$ length. The cut green rods were firstly dried at $40^{\circ} \mathrm{C}$ for $10 \mathrm{~h}$ to remove moisture. The dried rods were subsequently thermally sintered at $650^{\circ} \mathrm{C}$ with a heating rate of $30^{\circ} \mathrm{C} / \mathrm{h}$ to remove organic additives and lubricant. Finally, the samples were put into a BN-coated graphite crucible and sintered in a graphite resistance furnace (High multi-5000, Fijidempa Co. Ltd., Osaka, Japan) at $1800^{\circ} \mathrm{C}$ under $0.525 \mathrm{MPa}$ nitrogen $(99.999 \%)$ atmosphere for $2 \mathrm{~h}$ with a heating rate of $15^{\circ} \mathrm{C} / \mathrm{min}$, no powder bed was covered on the samples during sintering.

\subsection{Examination of properties}

Bulk density of the samples after extrusion was determined by measuring the dimensions and weight, and porosity was calculated from the bulk density and theoretical density, which was calculated by the rule of mixtures. The bulk density and open porosity of the samples after other stages were measured by the Archimedes displacement method using distilled water.

The samples after sintering were machined into test bars of $30 \times 4 \times 3 \mathrm{~mm}^{3}$ for bending strength measurement. All surfaces of the sintered test bars were finally ground on an 800-grit diamond wheel, and the edges were tilted. The directions of both the diamond grinding and tilting were parallel to that of the bar length. All three-point bending strengths were measured with a span of $16 \mathrm{~mm}$ at a cross-head speed of $0.5 \mathrm{~mm} / \mathrm{min}$, using Instron universal testing machine. Fracture toughness was determined by a single-edge precracked beam (SEPB). The precracked specimens were tested at a stroke rate of $0.05 \mathrm{~mm} / \mathrm{min}$ using a three-point bending fixture with a span of $16 \mathrm{~mm}$ using the same testing machine as the bending strength test.

Crystalline phases were identified by X-ray diffraction (XRD) (D/MAX-2400X, Rigaku Co. Ltd., Tokyo, Japan) analysis using $\mathrm{CuK}_{\alpha}$ radiation. The microstructures were characterized by scanning electron microscope (SEM, S-2700, Hitachi, Japan). The fracture surfaces after the bending test and the polished surfaces, coated with gold, were used for SEM observation, respectively.

\section{Results and discussion}

\subsection{Effect of CMC as binder}

The solution concentration for CMC as binder was $2.5 \%$, $15 \%$ PEG of molecular weight 10000 as plasticizer. The compositions of the test samples with 5 wt.\% $\mathrm{Y}_{2} \mathrm{O}_{3}$ and $\mathrm{Lu}_{2} \mathrm{O}_{3}$ are listed in table 1 . The most stable and suitable slurry was obtained from a solid slurry content of $65 \sim 80 \%$, when the slurry was too diluted, it was not easy to form, and too dried, it was difficult to extrude, so the solid slurry content of $70 \sim 75 \%$ and extrusion pressure of $0.5 \sim 1.0 \mathrm{MPa}$ were chosen in the experiment.

Figure 2 shows XRD patterns of samples 1 and 2, the main phase was $\beta-\mathrm{Si}_{3} \mathrm{~N}_{4}$, without $\alpha-\mathrm{Si}_{3} \mathrm{~N}_{4}$ phase detected, and confirming a full transformation from $\alpha-\mathrm{Si}_{3} \mathrm{~N}_{4}$ to $\beta$ $\mathrm{Si}_{3} \mathrm{~N}_{4}$ during sintering by a solution-precipitation process. The acicular microstructure was believed that it was a result of the anisotropic growth of the hexagonal $\mathrm{Si}_{3} \mathrm{~N}_{4}$ grains to maximize the area of the low energy (100) prismatic planes. The newly formed $\beta-\mathrm{Si}_{3} \mathrm{~N}_{4}$ phase had an elongated hexagonal rod morphology, which formed an interlocking microstructure and was considered responsible for the superior mechanical properties of $\mathrm{Si}_{3} \mathrm{~N}_{4}$ ceramics (Lper 1995). No second phase particles were identified in 
Table 1. Compositions of the test samples with $5 \mathrm{wt} \% \mathrm{Y}_{2} \mathrm{O}_{3}$ and $\mathrm{Lu}_{2} \mathrm{O}_{3}$.

\begin{tabular}{lcccc}
\hline Samples & Composition in mass & PEG (\%) & CMC (\%) & Castor oil (\%) \\
\hline 1 & $5 \% \mathrm{Y}_{2} \mathrm{O}_{3}+95 \% \mathrm{Si}_{3} \mathrm{~N}_{4}$ & 35 & 20 & 8 \\
2 & $5 \% \mathrm{Lu}_{2} \mathrm{O}_{3}+95 \% \mathrm{Si}_{3} \mathrm{~N}_{4}$ & 35 & 20 & 8 \\
\hline
\end{tabular}

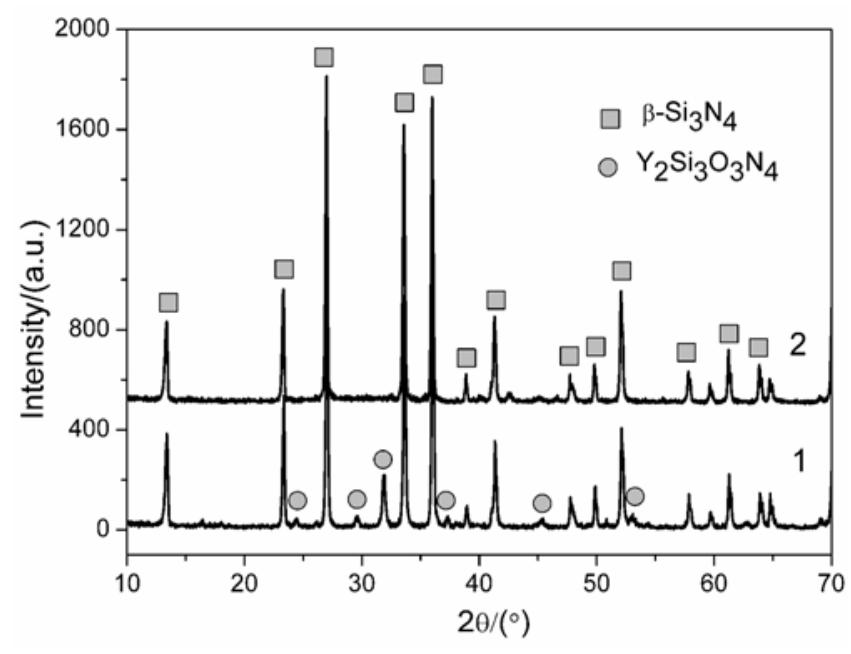

Figure 2. XRD patterns of samples 1 and 2 .

sample 2, indicating that $\mathrm{Lu}_{2} \mathrm{O}_{3}$ were dissolved in the eutectic liquid during the sintering process. However, a small amount of $\mathrm{Y}_{2} \mathrm{Si}_{3} \mathrm{O}_{3} \mathrm{~N}_{4}$ exists in sample 1, formed by the reaction between $\mathrm{Y}_{2} \mathrm{O}_{3}, \mathrm{Si}_{3} \mathrm{~N}_{4}$ and $\mathrm{SiO}_{2}$.

SEM micrographs of fracture surfaces of the sintered samples with different sintering additives are given in figure 3. It was obvious that these samples showed a typical bimodal microstructure composed of large elongated $\beta-\mathrm{Si}_{3} \mathrm{~N}_{4}$ grains and small $\beta-\mathrm{Si}_{3} \mathrm{~N}_{4}$ matrix grains. Compared with samples 1 and 2, it was striking that sample 2 had a small amount of larger elongated $\beta-\mathrm{Si}_{3} \mathrm{~N}_{4}$ grains and a finer, higher aspect ratio of $\beta-\mathrm{Si}_{3} \mathrm{~N}_{4}$ matrix grains. The microstructure of the porous $\mathrm{Si}_{3} \mathrm{~N}_{4}$ ceramics added with $\mathrm{Lu}_{2} \mathrm{O}_{3}$ was better than those added with $\mathrm{Y}_{2} \mathrm{O}_{3}$, the explanation for the microstructural formation for the different ceramics with different types of oxides had been well documented (Yang et al 2006; Yu et al 2008).

Figure 4 shows the density, porosity and three-point bending strength (flexural strength) of the porous $\mathrm{Si}_{3} \mathrm{~N}_{4}$ ceramics. The porous $\mathrm{Si}_{3} \mathrm{~N}_{4}$ ceramics with three-point bending strengths of $42 \cdot 18 \pm 12$ and $57.63 \pm 15 \mathrm{MPa}$ and porosities of $45.56 \%$ and $47.32 \%$, respectively were obtained. The resultant porous $\mathrm{Si}_{3} \mathrm{~N}_{4}$ ceramics exhibited much lower strength in comparison with other porous $\mathrm{Si}_{3} \mathrm{~N}_{4}$ ceramics (Yang et al 2000, 2002, 2003a). The explanations are given as follows. The molecular structural formulas of CMC and PEG are shown in figure 5. $\mathrm{CMC}$ acted as a binder and effective deflocculant simul- taneously because of the polar groups such as $-\mathrm{CH}_{2} \mathrm{OCH}_{2} \mathrm{COONa}$ and $-\mathrm{OH}$, adding $\mathrm{CMC}$ conferred to the suspensions a shear thinning behaviour, especially in the lower shear rate range, followed by a trend to a Newtonian fluid behaviour. This flow behaviour was typical of well dispersed and highly concentrated suspensions (Tarì 1998a, b). So CMC was very good for use in slip casting molding, but went against extrusion molding. The defects were more easily generated in molding process because of low viscosity of the slurries, so the prepared porous $\mathrm{Si}_{3} \mathrm{~N}_{4}$ ceramics had lower flexural strength. And adding 15\% PEG of molecular weight, 10000, as plasticizer, the molecular chain rigidities tended to increase with increasing molecular weight, which induced extrusion molding with difficulty. Even if the green body was formed, the molding samples were more easily to produce a great number of micro cracks because of release of residual stress produced in resisting molecular chain deformability in drying, debinding and sintering, the resultant porous $\mathrm{Si}_{3} \mathrm{~N}_{4}$ ceramics showed worse mechanical properties due to a great number of micro cracks. So the PEG of molecular weight, 10000, was not suitable for plasticizer, and PEG of molecular weight, 1000, was chosen in the next experiment.

\subsection{Effect of MC and HPMC as binder}

$2 \%, 4 \% \mathrm{MC}$ and 4\% HPMC were selected as binder and $15 \%$ PEG of molecular weight, 1000 , as plasticizer. The compositions of the test samples with different concentrations of MC and HPMC are listed in table 2.

Table 3 shows mechanical properties of the porous $\mathrm{Si}_{3} \mathrm{~N}_{4}$ ceramics. The results showed that the mechanical properties of the sintering sample with compositions of 4\% MC + 1000 PEG and 4\% HPMC + 1000 PEG, and a solid slurry content of $75 \%$ showed very excellent mechanical properties in comparison with other compositions. Although the green density of the sample with composition of $2 \% \mathrm{MC}+1000$ PEG was lower, the density of porous $\mathrm{Si}_{3} \mathrm{~N}_{4}$ ceramics was similar to the other compositions due to the shrinking in the sintering process, which was very detrimental for mechanical properties.

For analysing three-point bending strength distribution of the ceramics material, Weibull (1951) proposed a two-parameter distribution function to characterize the strength of brittle materials. More clearly, a low $m$ value indicates non-uniform distribution of highly variable 

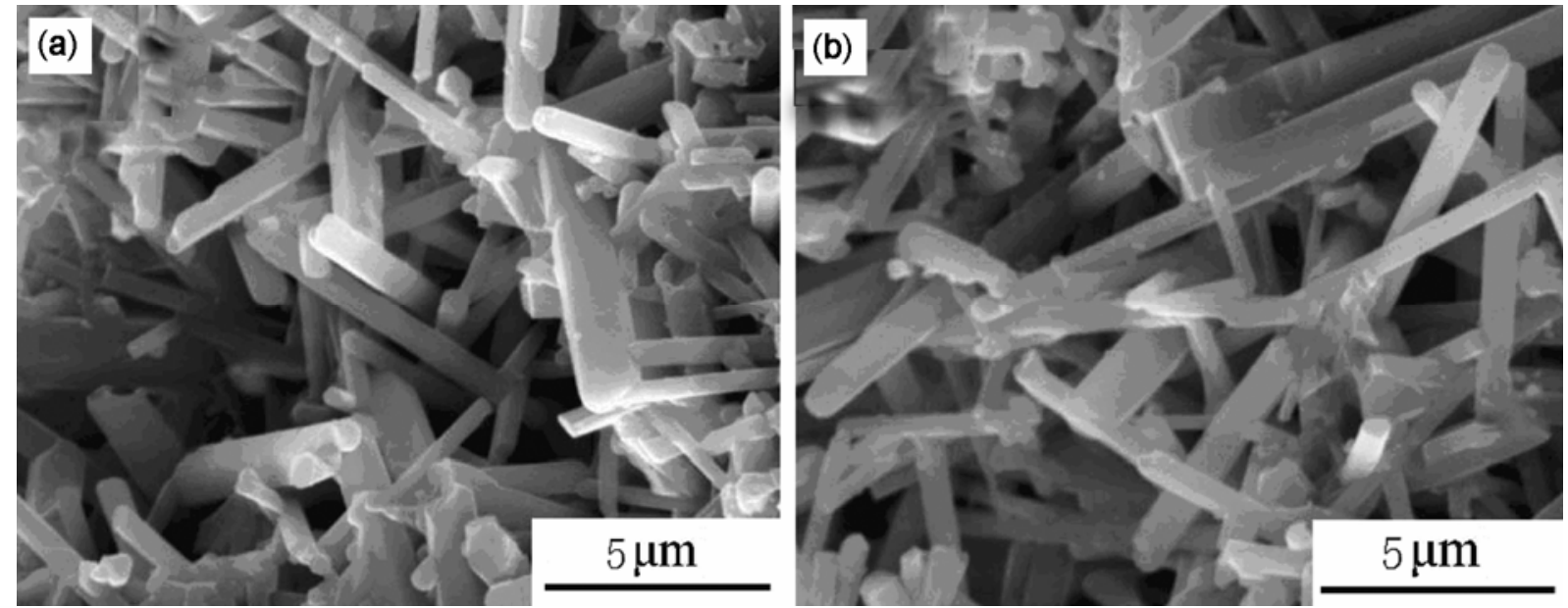

Figure 3. SEM micrographs of (a) sample 1 and (b) sample 2.

Table 2. Compositions of the test samples with different concentrations of MC and HPMC.

\begin{tabular}{lccc}
\hline Compositions (wt.\%) & Binder (\%) & PEG (\%) & Castor oil (\%) \\
\hline $5 \% \mathrm{Lu}_{2} \mathrm{O}_{3}+95 \% \mathrm{Si}_{3} \mathrm{~N}_{4}+2 \% \mathrm{MC}$ (concentration) & 25 & 5 & 4 \\
$5 \% \mathrm{Lu}_{2} \mathrm{O}_{3}+95 \% \mathrm{Si}_{3} \mathrm{~N}_{4}+4 \% \mathrm{MC}$ (concentration) & 25 & 5 & 4 \\
$5 \% \mathrm{Lu}_{2} \mathrm{O}_{3}+95 \% \mathrm{Si}_{3} \mathrm{~N}_{4}+4 \% \mathrm{HPMC}$ (concentration) & 25 & 5 & 4 \\
\hline
\end{tabular}

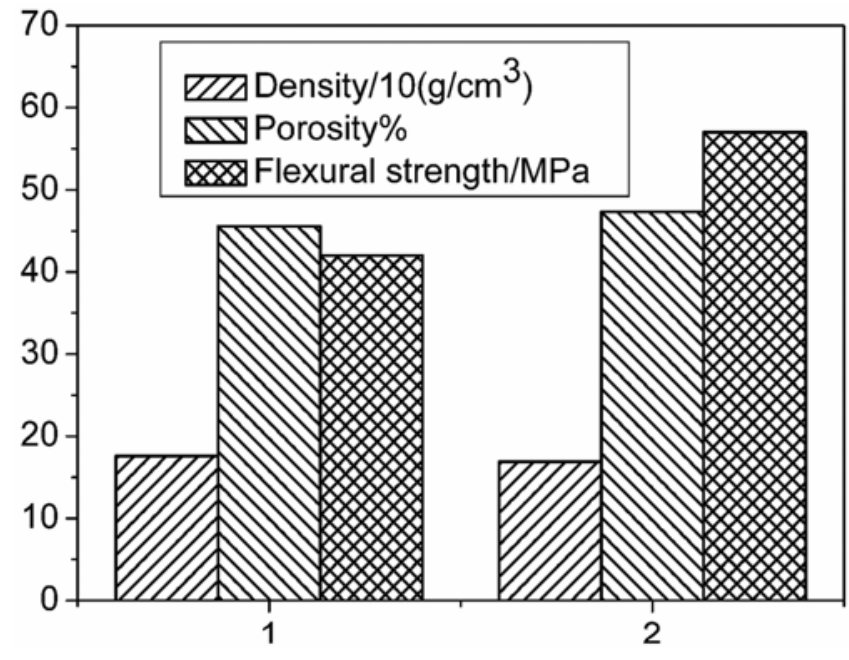

Figure 4. Density, porosity and three-point bending strength (flexural strength) of porous $\mathrm{Si}_{3} \mathrm{~N}_{4}$ ceramics.

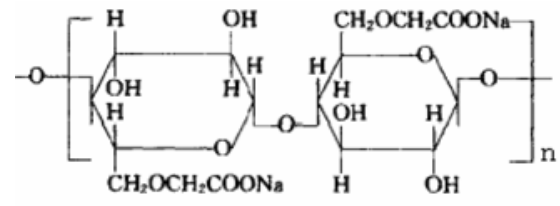

(a)
$\mathrm{HO}+\mathrm{CH}_{2} \mathrm{CH}_{2} \mathrm{O}+{ }_{n} \mathrm{H}$

(b)
Figure 5. Molecular structural formula of (a) CMC and (b) PEG.

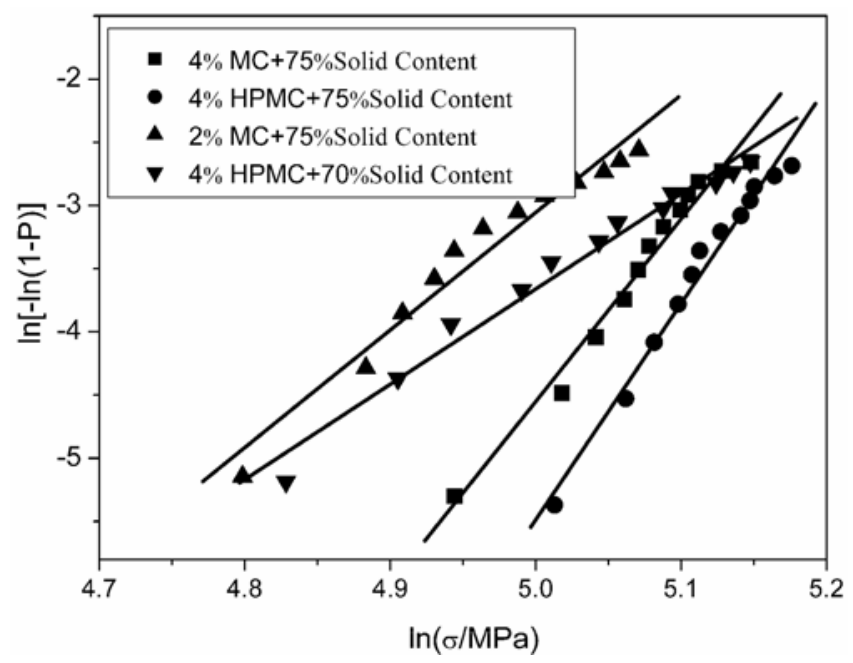

Figure 6. Weibull statistics analysis results of the samples adding different binder and solid slurry contents.

crack length (broad strength distribution), while a high $m$ value implicates uniform distribution of highly homogeneous flaws with narrower strength distribution. Typically, for structural ceramics, $m$ varies between 5 and 30 , depending on the processing conditions (Bazant 2004; Zeng et al 2006), so the Weibull distribution function is widely used to characterize the fracture strength of the porous $\mathrm{Si}_{3} \mathrm{~N}_{4}$ ceramics. Figure 6 shows Weibull statistics analysis where failure probability was plotted versus 

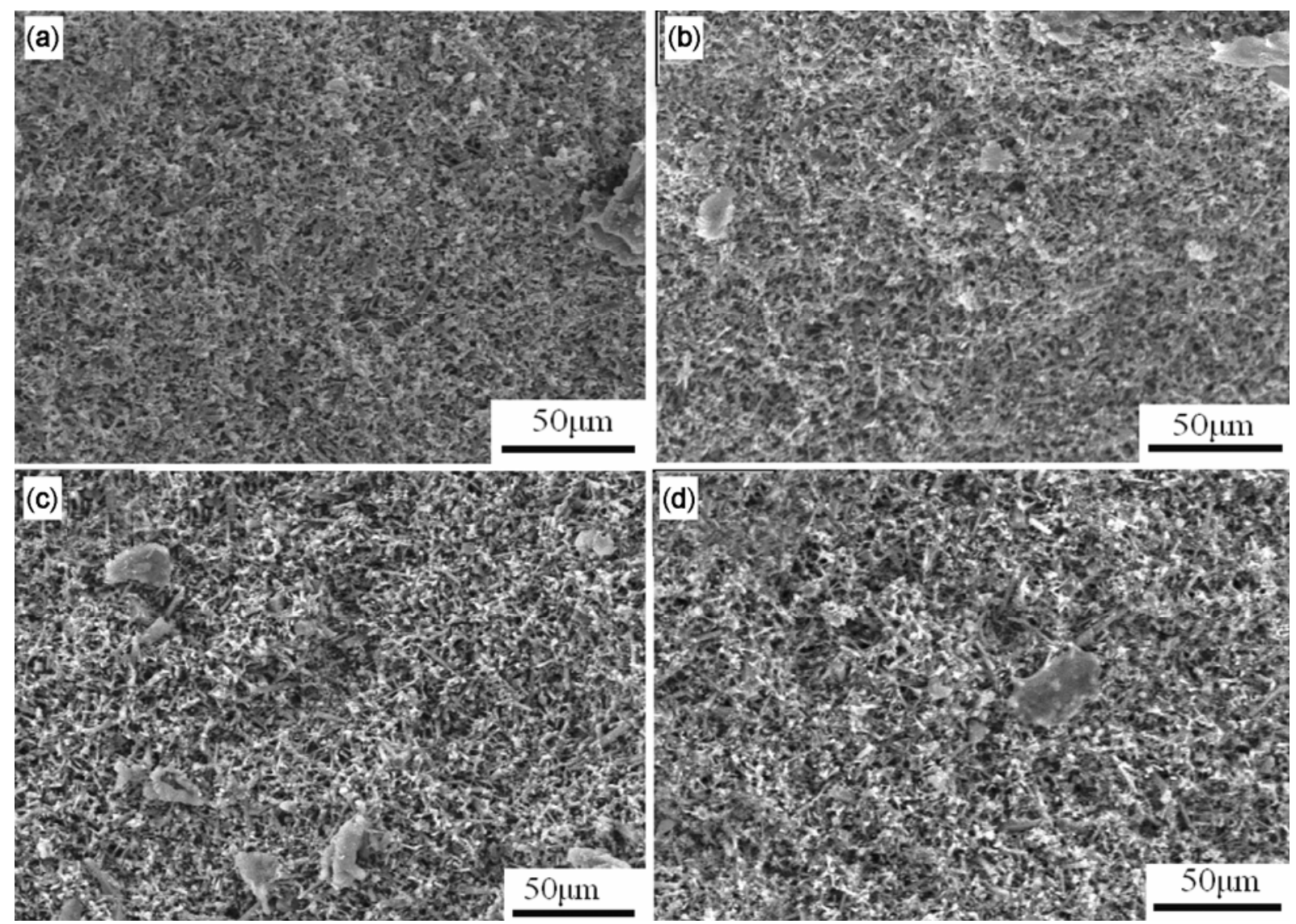

Figure 7. SEM micrographs of porous $\mathrm{Si}_{3} \mathrm{~N}_{4}$ ceramics with different concentrations of binder and solid slurry contents. (a) 4\% HPMC + solid slurry content $75 \%$; (b) 4\% MC + solid slurry content $75 \%$; (c) $2 \% \mathrm{MC}+$ solid slurry content $75 \%$ and (d) $4 \%$ HPMC + solid slurry content $70 \%$.
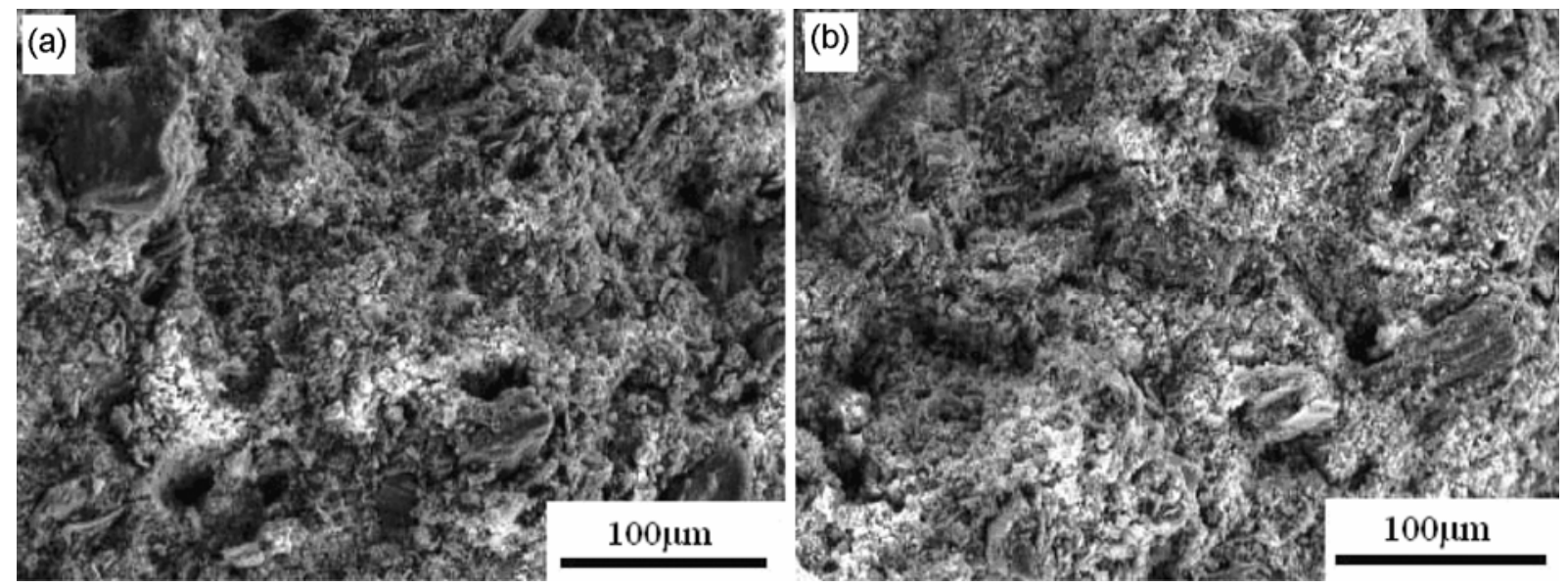

Figure 8. SEM micrographs of the green body after sintering with compositions of (a) 4\% MC and (b) $4 \%$ HPMC.

applied load. All the strength data are tabulated in table 4. For sample with compositions of $4 \% \mathrm{MC}+1000 \mathrm{PEG}$ and $4 \%$ HPMC +1000 PEG and a solid slurry content of $75 \%$, the Weibull modulus $(m)$ was very high, which indicated uniform distribution of highly homogeneous flaws with narrower strength distribution.
Figure 7 gave SEM micrographs of fracture surfaces of the sintered samples with different solid slurry contents and binder. It was obvious that the samples showed a typical bimodal microstructure composed of large elongated $\beta-\mathrm{Si}_{3} \mathrm{~N}_{4}$ grains and small $\beta-\mathrm{Si}_{3} \mathrm{~N}_{4}$ matrix grains. The microstructure of the porous $\mathrm{Si}_{3} \mathrm{~N}_{4}$ ceramics added 
Table 3. Mechanical properties of the porous $\mathrm{Si}_{3} \mathrm{~N}_{4}$ ceramics.

\begin{tabular}{|c|c|c|c|c|}
\hline \multirow{2}{*}{$\begin{array}{l}\text { Solid slurry content (\%) } \\
\text { Compositions }\end{array}$} & \multicolumn{2}{|c|}{$75 \%$} & \multicolumn{2}{|c|}{$70 \%$} \\
\hline & $2 \% \mathrm{MC}+\mathrm{PEG}$ & $4 \% \mathrm{MC}+\mathrm{PEG}$ & 4\% HPMC + PEG & $4 \% \mathrm{HPMC}+\mathrm{PEG}$ \\
\hline Green density $\left(\mathrm{g} \cdot \mathrm{cm}^{-3}\right)$ & $1 \cdot 66$ & $1 \cdot 69$ & 1.71 & $1 \cdot 70$ \\
\hline Green porosity (\%) & $37 \cdot 36$ & $35 \cdot 39$ & $35 \cdot 62$ & $36 \cdot 43$ \\
\hline Density $\left(\mathrm{g} \cdot \mathrm{cm}^{-3}\right)$ & $1 \cdot 86$ & 1.85 & $1 \cdot 91$ & $1 \cdot 95$ \\
\hline Porosity (\%) & $42 \cdot 92$ & $43 \cdot 08$ & $41 \cdot 70$ & $40 \cdot 29$ \\
\hline$\sigma_{\mathrm{b}}(\mathrm{MPa})$ & $141 \cdot 02 \pm 22$ & $160 \cdot 35 \pm 24$ & $166 \cdot 53 \pm 20$ & $152 \cdot 70 \pm 25$ \\
\hline $\mathrm{K}_{\mathrm{IC}} /\left(\mathrm{MPa} \cdot \mathrm{m}^{1 / 2}\right)$ & $2 \cdot 21 \pm 0 \cdot 3$ & $2 \cdot 39 \pm 0 \cdot 2$ & $2 \cdot 45 \pm 0 \cdot 2$ & $2 \cdot 34 \pm 0 \cdot 1$ \\
\hline
\end{tabular}

Table 4. Weibull modulus ( $\mathrm{m}$ ) of the samples with different binder and solid slurry contents.

\begin{tabular}{llc}
\hline $\begin{array}{l}\text { Solid slurry } \\
\text { content (\%) }\end{array}$ & $\begin{array}{c}\text { Compositions } \\
(\text { wt.\%) }\end{array}$ & $\begin{array}{c}\text { Weibull } \\
\text { modulus (m) }\end{array}$ \\
\hline 75 & 2\% MC + PEG & $15 \cdot 84$ \\
& $4 \%$ MC + PEG & 18.38 \\
70 & $4 \%$ HPMC + PEG & $20 \cdot 75$ \\
& $4 \%$ HPMC + PEG & 13.42 \\
\hline
\end{tabular}

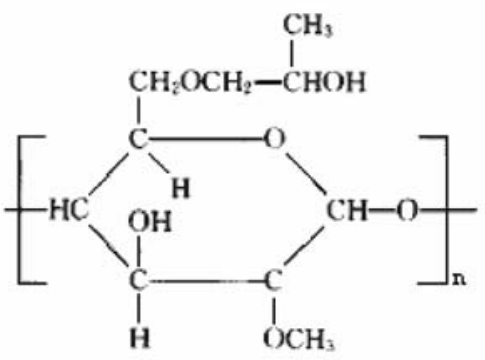

(a)

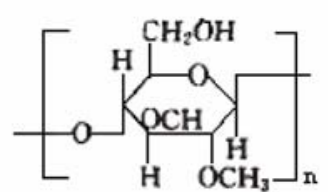

(b)
Figure 9. Molecular structural formula of (a) HPMC and (b) MC.

with compositions of 4\% HPMC +1000 PEG and 4\% $\mathrm{MC}+1000$ PEG and a solid slurry content of $75 \%$ were better than those added with compositions of $2 \% \mathrm{MC}$, and a solid slurry content of $70 \%$. It was reasonably believed that the concentration of binders and solid slurry content had great effect on properties of porous $\mathrm{Si}_{3} \mathrm{~N}_{4}$ ceramics.

Figure 8 showed SEM micrographs of samples after debinding. Compared with two micrographs, the micrograph with $4 \%$ HPMC was more uniform than that of $4 \%$ MC. Figure 9 showed the molecular structural formula of MC and HPMC. The hydroxyl in the molecular structural formula of MC was close to the molecular ring, and the hydroxyl in the molecular structural formula of HPMC was connected with long molecular groups, so molecular polarity of HPMC was more stronger than MC, HPMC was easier to adsorb moisture and keep humidity, which had a good performance in the drying and debinding process, and not easier to deform and crack.

\section{Conclusions}

Green bodies of porous $\mathrm{Si}_{3} \mathrm{~N}_{4}$ ceramics were shaped by extrusion technique using $\mathrm{CMC}, \mathrm{MC}$ and HPMC as binder in subsequent process stages. The solid slurry content of $70 \sim 75 \%$ and extrusion pressure of $0.5 \sim 1.0 \mathrm{MPa}$ had played a decisive role in the smooth realization of extrusion molding. The resultant porous $\mathrm{Si}_{3} \mathrm{~N}_{4}$ ceramics with high porosity, well-developed microstructures, and outstanding mechanical properties were obtained. Using $15 \%$ PEG of molecular weight, 1000 , as plasticizer, castor oil as lubricant and glycerol as moisturizing agent, $4 \%$ MC and HPMC were most suitable for extrusion molding. The porous $\mathrm{Si}_{3} \mathrm{~N}_{4}$ ceramics were obtained with excellent properties using $4 \% \mathrm{HPMC}$ as binder, the density of $1.91 \mathrm{~g} \cdot \mathrm{cm}^{-3}$, porosity of $41.70 \%$, and three-point bending strength of $166.53 \pm 20 \mathrm{MPa}$, toughness fracture of $2 \cdot 45 \pm 0.2 \mathrm{MPa} \cdot \mathrm{m}^{1 / 2}$ and Weibull modulus of 20.75 .

\section{Acknowledgements}

This work was supported by the National Natural Science Foundation of China (No. 50772086) and the High-Tech R\&D Program of China (863, No. 2007AA03Z558), and by Research Fund for the Doctoral Program of Higher Education under contract No. 20060698008.

\section{References}

Bazant Z P 2004 Prob. Eng. Mech. 19307

Corbin S F, Lee J and Qiao X 2001 J. Am. Ceram. Soc. 84 41

Haslam J J, Beroth K E and Lange F F 2000 J. Eur. Ceram. Soc. 20607

Isobe T, Tomita T, Kameshima Y, Nakajima A and Okada K 2006 J. Eur. Ceram. Soc. 26957

Isobe T, Kameshima Y, Nakajima A and Okada K 2007 J. Eur. Ceram. Soc. 2761

Kawai C and Yamakawa A 1997 J. Am. Ceram. Soc. 802705

Kaya C and Butler E G 2002 J. Eur. Ceram. Soc. 221917

Lper A M 1995 Phase diagrams on advanced ceramics: chemical and metallurgical products $\Pi[C]$ (ed.) $\mathrm{Y} \mathrm{T}$ Tseng (PA: Towanda) pp 127-128

Oh S T, Tajima K I, Ando M and Ohji T $2000 \mathrm{~J}$. Am. Ceram. Soc. 831314 
Raupp-Pereira F, Ribeiro M J, Segadaes A M and Labrincha J A 2007 J. Eur. Ceram. Soc. 272333

Shigegaki Y, Brito M E, Hirao K, Toriyama M and Kanzaki S 1997 J. Am. Ceram. Soc. 80495

Tarì G, Ferreira J M F and Lyckfeldt O 1998a J. Eur. Ceram. Soc. 18386

Tarì G, Fonseca A T and Ferreira J M F 1998b Br. Ceram. Trans. 97259

Treischel C C and Emrich E W 1946 J. Am. Ceram. Soc. 29 129

Weibull W 1951 J. Appl. Mech. 18293

Yang J, Yang J F, Shan S Y and Gao J Q 2006 J. Am. Ceram. Soc. 893843
Yang J F, Ohji T and Niihara K 2000 J. Am. Ceram. Soc. 83 2094

Yang J F, Ohji T, Kanzaki S, Díaz A and Hampshire S 2002 J. Am. Ceram. Soc. 851512

Yang J F, Deng Z Y and Ohji T 2003a J. Eur. Ceram. Soc. 23 371

Yang J F, Zeng Y P, Ohji T, Kanzaki S and Zhang G J 2003b J. Ceram. Soc. Jpn 111758

Yu F L, Yang J F, Xue Y H, Gao J Q and Jin Z H 2008 J. Chin. Ceram. Soc. 361037

Zeng L K, Wang H and Luo M H 2006 Preparation and application of porous functional ceramics (Beijing: Chemical Industry Publishers) p. 95 